\title{
The Effects of the Anti-aging Protein Klotho on Mucociliary Clearance
}

\author{
Jaleesa Garth ${ }^{1}$, Molly Easter ${ }^{1}$, Elex Skylar Harris ${ }^{1,2}$, Juliette Sailland ${ }^{3}$, Lisa Kuenzi ${ }^{3}$, \\ Samuel Chung 3,4, John S. Dennis ${ }^{3,4}$, Nathalie Baumlin ${ }^{3,4}$, Adegboyega T. Adewale ${ }^{4}$, \\ Steven M. Rowe ${ }^{1,2}$, Gwendalyn King ${ }^{5}$, Christian Faul ${ }^{6}$, Jarrod W. Barnes ${ }^{1,2}$, \\ Matthias Salathe ${ }^{3,4}$ and Stefanie Krick ${ }^{1,2 *}$
}

${ }^{1}$ Division of Pulmonary, Allergy and Critical Care Medicine, Department of Medicine, University of Alabama at Birmingham, Birmingham, AL, United States, ${ }^{2}$ Gregory Fleming James Cystic Fibrosis Research Center, The University of Alabama at Birmingham, Birmingham, AL, United States, ${ }^{3}$ Division of Pulmonary, Allergy, Critical Care and Sleep Medicine, Department of Medicine, University of Miami Miller School of Medicine, Miami, FL, United States, ${ }^{4}$ Division of Pulmonary, Critical Care, and Sleep Medicine, Department of Internal Medicine University of Kansas Medical Center, Kansas City, KS, United States, ${ }^{5}$ Department of Biology, Creighton University, Omaha, NE, United States, ${ }^{6}$ Division of Nephrology, Department of Medicine, The University of Alabama at Birmingham, Birmingham, AL, United States

$\alpha-k$ lotho $(\mathrm{KL})$ is an anti-aging protein and has been shown to exert anti-inflammatory and anti-oxidative effects in the lung and pulmonary diseases such as chronic obstructive pulmonary disease (COPD) and cystic fibrosis. The current study investigated the direct effect of $\mathrm{KL}$ on the bronchial epithelium in regards to mucociliary clearance parameters.

OPEN ACCESS

Edited by:

Argyrios Tzouvelekis, Alexander Fleming Biomedical Sciences Research Center, Greece

Reviewed by:

Eliza Tsitoura

University of Crete, Greece Eleanna Kaffe,

Yale University, United States

${ }^{*}$ Correspondence: Stefanie Krick skrick@uabmc.edu

Specialty section: This article was submitted to Pulmonary Medicine, a section of the journal

Frontiers in Medicine

Received: 30 August 2019 Accepted: 24 December 2019 Published: 24 January 2020

Citation:

Garth J, Easter M, Skylar Harris E,

Sailland J, Kuenzi L, Chung S, Dennis JS, Baumlin N, Adewale AT, Rowe SM, King G, Faul C, Barnes JW, Salathe M and Krick S (2020) The Effects of the Anti-aging Protein Klotho on Mucociliary Clearance. Front. Med. 6:339.

doi: 10.3389/fmed.2019.00339
Primary human bronchial and murine tracheal epithelial cells, cultured, and differentiated at the air liquid interface (ALI), were treated with recombinant $\mathrm{KL}$ or infected with a lentiviral vector expressing KL. Airway surface liquid (ASL) volume, airway ion channel activities, and expression levels were analyzed. These experiments were paired with ex vivo analyses of mucociliary clearance in murine tracheas from klotho deficient mice and their wild type littermates. Our results showed that klotho deficiency led to impaired mucociliary clearance with a reduction in ASL volume in vitro and ex vivo. Overexpression or exogenous $\mathrm{KL}$ increased $\mathrm{ASL}$ volume, which was paralleled by increased activation of the large-conductance, $\mathrm{Ca}^{2+}$-activated, voltage-dependent potassium channel (BK) without effect on the cystic fibrosis transmembrane conductance regulator (CFTR). Furthermore, $\mathrm{KL}$ overexpression downregulated $\mathrm{IL}-8$ levels and attenuated TGF- $\beta$-mediated downregulation of LRRC26, the $\gamma$ subunit of BK, necessary for its function in non-excitable cells. In summary, we show that $\mathrm{KL}$ regulates mucociliary function by increasing ASL volume in the airways possibly due to underlying BK activation. The KL mediated BK channel activation may be a potentially important target to design therapeutic strategies in inflammatory airway diseases when ASL volume is decreased.

Keywords: klotho, mucociliary clearance, TGF- $\beta$, airway surface liquid volume, calcium activated potassium channels

\section{INTRODUCTION}

As part of the innate defense mechanism, mucociliary clearance (MCC) protects the airway epithelium by trapping inhaled pathogens or particulate matter within the mucus layer and removing it from the airways through ciliary movement $(1,2)$. Proper function of MCC depends on both mucus production and mucus transport, which are affected by coordinated ciliary beating, 
sufficient ASL volume, and mucus viscosity (3). MCC can become compromised by dysregulation of any of these key components, which renders the airway and especially the airway epithelium susceptible to infection. By failing to transport mucus effectively, airways become obstructed which leads to inflammatory changes as commonly seen in diseases such as cystic fibrosis (CF), asthma or COPD (4-9).

ASL volume is regulated by ion fluxes across the apical airway epithelial membrane, which achieves a balance of sodium $\left(\mathrm{Na}^{+}\right)$ absorption and chloride $\left(\mathrm{Cl}^{-}\right)$secretion (10-12). The CFTR channel in part regulates chloride movement across the apical airway epithelial membrane to maintain airway fluid homeostasis and proper ciliary beating $(13,14)$. However, apical potassium $\left(\mathrm{K}^{+}\right)$secretion via BK channels has been increasingly recognized for its essential role in delivering an electrochemical driving force for apical chloride ion exit through CFTR and calciumactivated chloride channels (CaCC) (15). This regulated ion flux has been shown to help maintain ASL volume and MCC (1619), and dysregulation of these channels has been documented in the pathogenesis of a multitude of inflammatory airway diseases including CF and COPD (19-21).

The klotho protein (KL) exists in several forms including the full-length membrane form and a soluble circulating form, which results from either proteolytic cleavage or alternative splicing $(22,23)$. KL's interaction with fibroblast growth factor (FGF) 23 is well-documented: FGF23 and KL bind to FGF receptor 1 as a co-receptor, which has been shown to regulate phosphate and calcium homeostasis in the kidney and parathyroid gland (24). In addition, KL has been characterized as an anti-aging protein, exerting anti-oxidative, anti-inflammatory, and antiproliferative functions in the heart, lung, and kidney (25-28). We have previously shown that KL can protect the bronchial epithelium against transforming growth factor (TGF)- $\beta$-induced inflammation in CF lung disease (26). However, the role of KL on mucociliary clearance has not been evaluated. In this study, we investigated the effects of KL on ion flux across the airway epithelium and thereby ASL homeostasis.

\section{METHODS}

\section{Air Liquid Interface (ALI) Cell Culture}

Human bronchial epithelial cells from individuals without significant lung disease (HBEC) were isolated and cultured using the ALI model as described previously $(19,29)$. Institutional review board-approved consent for research was obtained by the Life Alliance Organ Recovery Agency of the University of Miami or the Life Center Northwest and the University of Alabama at Birmingham.

Murine tracheal epithelial cells (MTEC) from wild type mice and mice, homozygous for the klotho gene disruption (30), were isolated, cultured, and differentiated for 2-3 weeks according to an adapted protocol of You et al., as previously described $(26,31,32)$.

\section{$\mu$ OCT Analyses}

The $\mu$ OCT technique and analysis have been described previously (33-35). Briefly, CBF, MCT, and ASL height were directly evaluated via cross-sectional images of the airway epithelium using high acquisition speed and high resolution. Quantitative analysis of the images was achieved by use of ImageJ (36).

\section{Airway Surface Liquid (ASL) Volume in vitro} ASL volumes from HBECs and MTECs were quantified by meniscus scanning and data were analyzed using the software generously provided by Dr. Myerburg (University of Pittsburgh) (37).

\section{Electrophysiology}

Differentiated HBECs on Snapwell filters were mounted in Ussing chambers (Easymount chamber; Physiologic Instruments) connected to a VCC MC6 voltage clamp unit (Physiologic Instruments, San Diego, CA, USA) as previously described (37). For BK activity, basolateral membranes were permeabilized for $30 \mathrm{~min}$ with $20 \mu \mathrm{M}$ amphotericin $\mathrm{B}, 10 \mu \mathrm{M}$ nigericin, and $10 \mu \mathrm{M}$ valinomycin (whole cell short circuit current recordings do not distinguish $\mathrm{K}^{+}$efflux but measure net current, a combination of $\mathrm{K}^{+}$and $\mathrm{Cl}^{-}$efflux) (16). For assessment of BK currents, cells were exposed to a $\mathrm{K}^{+}$gradient in the presence of apically applied $10 \mu \mathrm{M}$ amiloride (Sigma-Aldrich \#A7410, St. Louis, MO, USA) and $10 \mu \mathrm{M}$ ATP (Sigma-Aldrich \#A1852). CFTR activity was assessed in non-permeabilized cells using apical $5 \mathrm{mM} \mathrm{Cl}^{-}$in the presence of apically applied $10 \mu \mathrm{M}$ amiloride and $10 \mu \mathrm{M}$ forskolin (Sigma-Aldrich \#F3917) followed by $10 \mu \mathrm{M} \mathrm{CFTR}_{\text {inh }} 172$ (Sigma-Aldrich \#C2992) as described previously $(14,37)$.

\section{ELISA}

An ultrasensitive IL-8 enzyme-linked immunosorbent assay (ELISA) from Invitrogen (Thermo Fisher, Waltham, MA, USA) was used as described previously (26).

\section{Murine $K l$ Overexpression in NHBEC Using a Lentiviral Expression System}

A full length murine $\alpha$-klotho, which was kindly provided by Dr. Kuro-o (38), was cloned into a p38 plasmid containing a puromycin resistance cassette. Lentiviral infection of normal HBEC and puromycin selection was done before differentiation as previously described $(26,32,39)$.

\section{Intracellular Calcium Imaging Using GCaMP6s Sensor}

Imaging was performed as previously described (40). A pEF1Puromycin-expressing GCaMP6s construct was designed using pGP-CMV-GCaMP6s (Addgene plasmid \#40753) gifted by Dr. Douglas Kim (41). NHBEC cultures were infected in an undifferentiated state with packaged lentiviruses to deliver pEF1-GCaMP6s. Cultures were allowed to fully-differentiate at the air-liquid interface ( $>4$ weeks) under constant puromycin selection $(1 \mu \mathrm{g} / \mathrm{ml})$. GCaMP6s-expressing cultures were perfused at room temperature with HEPES-buffered HBSS, $\mathrm{pH} 7.3$ at $250 \mu \mathrm{L} \mathrm{min} \mathrm{m}^{-1}$ (42). GSK1016790A (Tocris), HC-067047 (Tocris), $\alpha$-Klotho (Peprotech), and DMSO vehicle control (0.1\%; Sigma-Aldrich) were dissolved in HEPES-buffered HBSS 
and also perfused at $250 \mu \mathrm{L} \mathrm{min}{ }^{-1}$. GCaMP6s emissions were recorded every $3 \mathrm{~s}$ using MetaFluor (Molecular Devices). Data were analyzed as relative calcium levels $\left(\mathrm{F}_{\mathrm{x}} / \mathrm{F}_{0}\right)$ using IGOR software (WaveMetrics).

\section{Statistics}

Experimental data were analyzed with Prism8 (GraphPad Software, Inc., La Jolla, CA) as previously described (19) using Student's $t$ test and analysis of variance or Kruskal Wallis with appropriate post tests for at least three independent experiments. Significance was accepted at $p<0.05$.

\section{RESULTS}

\section{ASL Height and Volume Is Significantly Decreased in Tracheas From $\mathrm{kl}^{-/-}$ Deficient Mice}

To determine the relevance of KL on parameters of mucociliary function, we harvested tracheas from $\mathrm{kl}^{-/-}$mice and their wild type littermates, analyzing them using $\mu \mathrm{OCT}$ as previously described (3). Consistent with previous findings, we observed dilated airway spaces, consistent with emphysema, when compared to wild type littermates (Figure 1A). Interestingly,
A
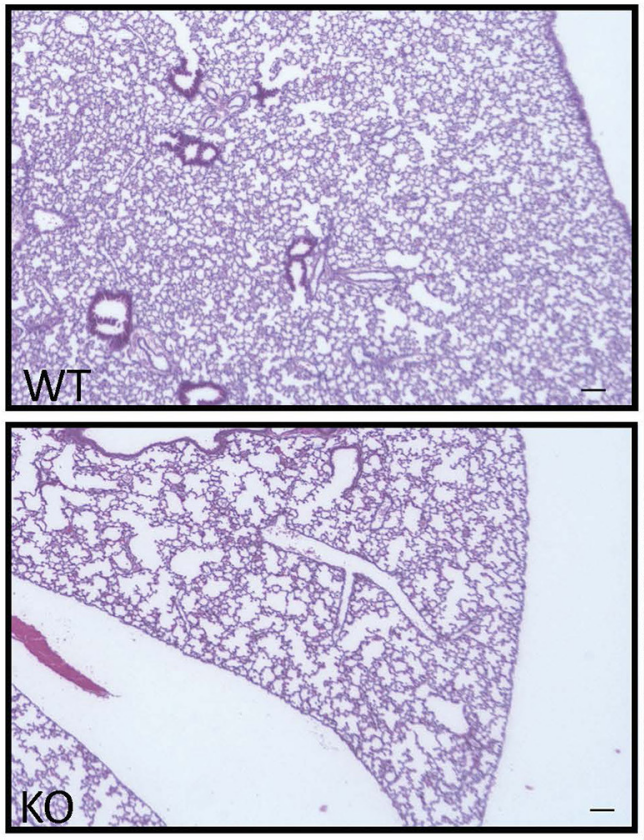

B

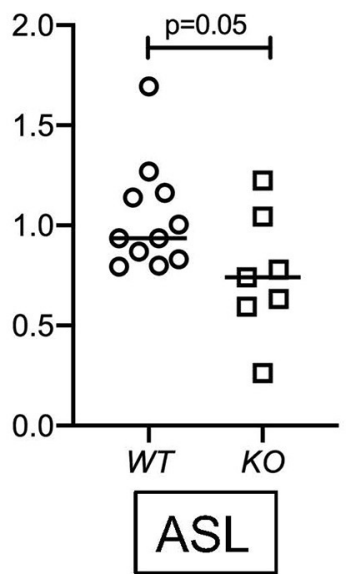

C

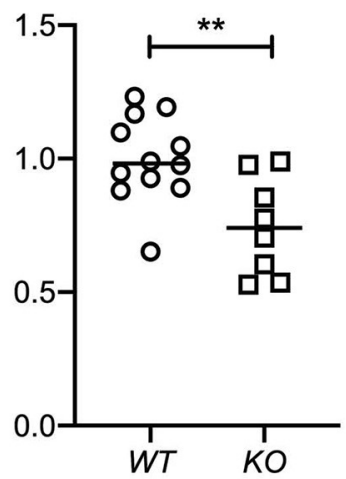

$\mathrm{CBF}$

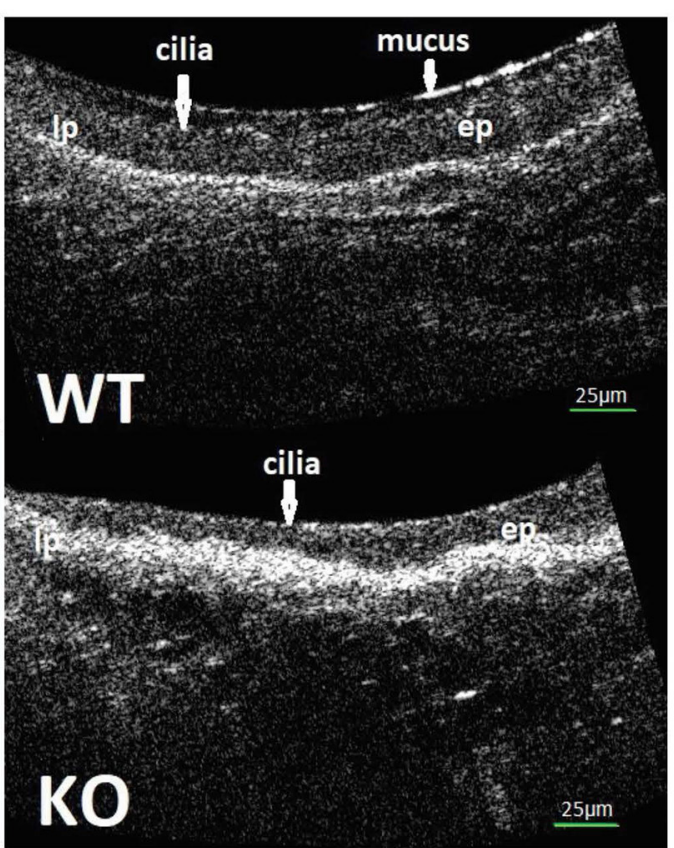

D

E

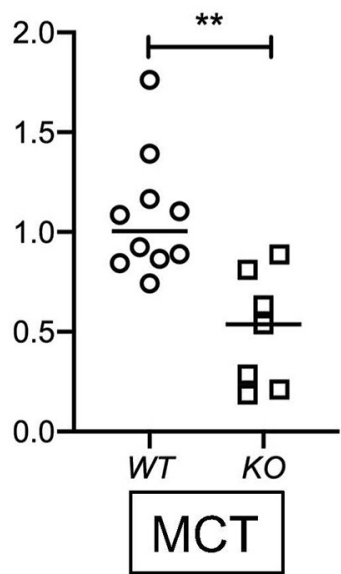

FIGURE 1 | (A) Representative images showing hematoxylin staining of whole lung sections from $\mathrm{kl}^{-/-}(\mathrm{KO})$ and $\mathrm{kl} / /+(\mathrm{WT})$ mice $(4 \mathrm{X}$ magnification, scale bar $=100$ $\mu \mathrm{m})$ and representative images of $\mu \mathrm{OCT}$ recordings from $\mathrm{Kl}^{-/-}(\mathrm{KO})$ and $\mathrm{kl}^{+/+}(\mathrm{WT})$ tracheas. (B) Comparison of fold changes in airway surface liquid (ASL) depth, (C) ciliary beat frequency (CBF), and (D) mucociliary transport ex vivo from excised tracheas of $\mathrm{K}^{-/-}(\mathrm{KO})$ and $\mathrm{K}^{+/+}(\mathrm{WT})$ mice using $\mu \mathrm{OCT}$. (E) Bronchoalveolar lavage fluid (BALF) analysis showing a trend increase of total neutrophil cell count in three representative WT and KO mice. Statistics: Student's $t$-test showing mean \pm S.D. with ${ }^{* *} p<0.01$, as indicated in appropriate graphs ( $n=7-11$ - animals per group). 
there was a significant decrease in ASL depth in the $\mathrm{kl}^{-/-}$ mice (Figure 1A right panel showing $\mu \mathrm{OCT}$ images and Figure 1B), and decreased ciliary beat frequency (CBF) and mucociliary transport (MCT) (Figures 1C,D). Previously, we and others have shown that $\mathrm{kl}^{-/-}$mice have a significant increase in total cell count and macrophage/monocytes in bronchoalveolar lavage (BAL) fluid indicating airway inflammation (43). Consistent with these previous findings, we show here also increased neutrophils in BAL fluid from $\mathrm{kl}^{-/-}$lungs when compared to wild type lungs (Figure 1E). In summary, klotho deficient mice show emphysema, lung inflammation and a decrease in ASL depth, CBF resulting in impaired MCT.

\section{In vitro Effects of Klotho on ASL Volume Regulation}

To validate our ex vivo data, we isolated primary murine tracheal epithelial cells (MTECs) and differentiated them at the ALI for 3-4 weeks until cilia and mucus were present as shown previously (43). MTECs, isolated from $\mathrm{kl}^{-/-}$mice also showed a significant decrease in their baseline ASL volume (Figure 2A). When primary human bronchial epithelial ALI cultures (HBEC) from control lungs were stimulated with TGF$\beta$, there was a significant decrease in ASL volume, consistent with the known deleterious effects of TGF- $\beta$ signaling on ion transport in non-CF epithelia (44). Supplementation of these cultures with human recombinant klotho protein mildly increased ASL volume after $24 \mathrm{~h}$ but did not attenuate the TGF- $\beta$ response within 24 or $48 \mathrm{~h}$ (Figure 2B). Since we experienced significant loss of activity of the recombinant klotho protein after short storage time or a freeze thaw cycle, we developed a lentiviral overexpression system of murine full length klotho in our ALI cultures (26). Assessment of these differentiated klotho overexpressing ALI cultures showed a significant increase in ASL volume after $24 \mathrm{~h}$, when compared to control-infected ALI cultures. Additionally, the TGF- $\beta$-mediated reduction in ASL volume was also attenuated in the klotho overexpressing cultures at $48 \mathrm{~h}$ (Figure 2C).
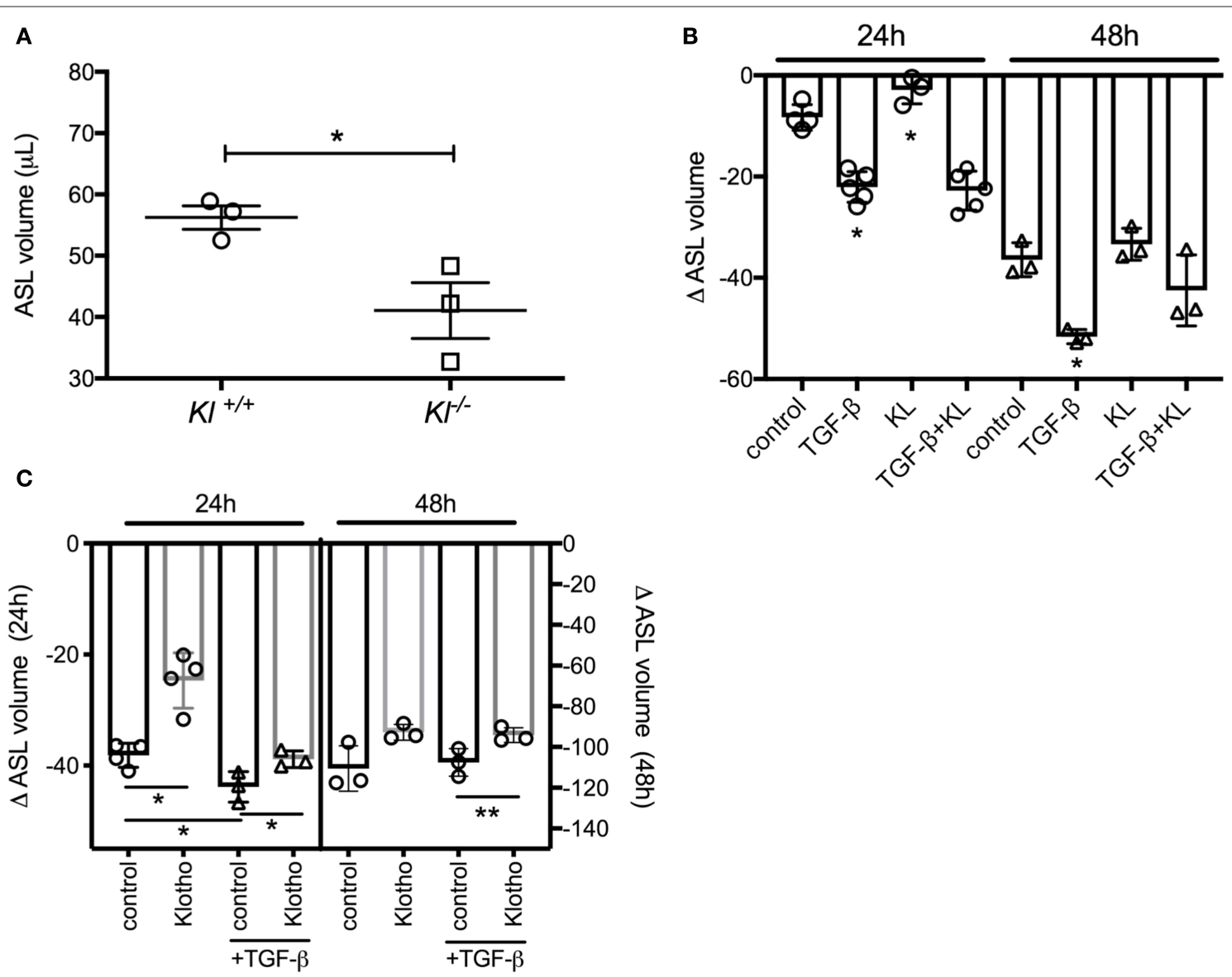

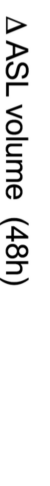

FIGURE 2 | (A) Dot plot showing a significant decrease of ASL volume in murine tracheal epithelial cells (MTECs), isolated from $\mathrm{kl}^{-/-}$mice and their wild type littermates and using meniscus scanning. (B) Bar graphs indicating ASL volume change in human bronchial epithelial cells (HBEC), differentiated at the ALI interface and treated with TGF- $\beta(2.5 \mathrm{ng} / \mathrm{ml}) \pm$ recombinant $\mathrm{KL}(100 \mathrm{ng} / \mathrm{ml})$ for 24 and $48 \mathrm{~h}$. (C) ASL volume change in HBEC, infected with either control or klotho and differentiated at the ALI interface and effect of TGF- $\beta(2.5 \mathrm{ng} / \mathrm{ml})$ for 24 and $48 \mathrm{~h}$. $\left(n=3\right.$ independent experiments showing mean \pm S.E. with ${ }^{*} P<0.05$ and $\left.{ }^{* *} P<0.01\right)$. 


\section{In vitro Effects of Klotho on HBEC Ion Channel Activation and Expression}

To assess underlying mechanisms how klotho regulates ASL volume, we used Ussing chamber measurements to assess CFTR, $\mathrm{BK}$, and $\mathrm{ENaC}$ activities; all channels expressed in ALI cultures and contributing to ASL volume regulation $(10,16)$. When ALI cultures were stimulated with recombinant KL or infected with KL lentiviral particles, only BK channel activity improved significantly at $24 \mathrm{~h}$ (Figure 3A). Lentiviral overexpression of $\mathrm{KL}$ also led to a persistent decrease of IL- 8 secretion in these cultures (Figure 3B). KL itself neither changed mRNA expression of CFTR, KCNMA1, and LRRC26 (two BK channel subunits) (Figure 3C), nor affected TGF- $\beta$ mediated changes after $24 \mathrm{~h}$ (Figure 3D), but there was attenuation of TGF- $\beta$-induced reduction in LRRC26 mRNA levels after $48 \mathrm{~h}$ (Figure 3E). This attenuation was also noted in the analysis of BK channel activity (Figure 3F). To further elucidate potential underlying mechanism for the described klotho effects, we could show that recombinant klotho transiently increased intracellular calcium in NHBEC cultures, comparable to a TRPV4 channel selective agonist (GSK1016790A) (Figures 3G,H). Pre-exposure to the TRPV4 inhibitor amplified the klotho effect on calcium further (Figure 3I). In summary, klotho attenuated IL-8 secretion in ALI cultures and may activate and partially restore the BK channel following TGF- $\beta$ treatment with intracellular calcium increase as a potential underlying mechanism, providing protection from a pro-inflammatory environment (Figure 4).

\section{DISCUSSION}

$\alpha$-Klotho is an anti-aging protein, originally known from its expression in the kidney (30). Mice deficient in klotho develop an aging phenotype including emphysematous lung changes and airway inflammation. We have previously shown that klotho

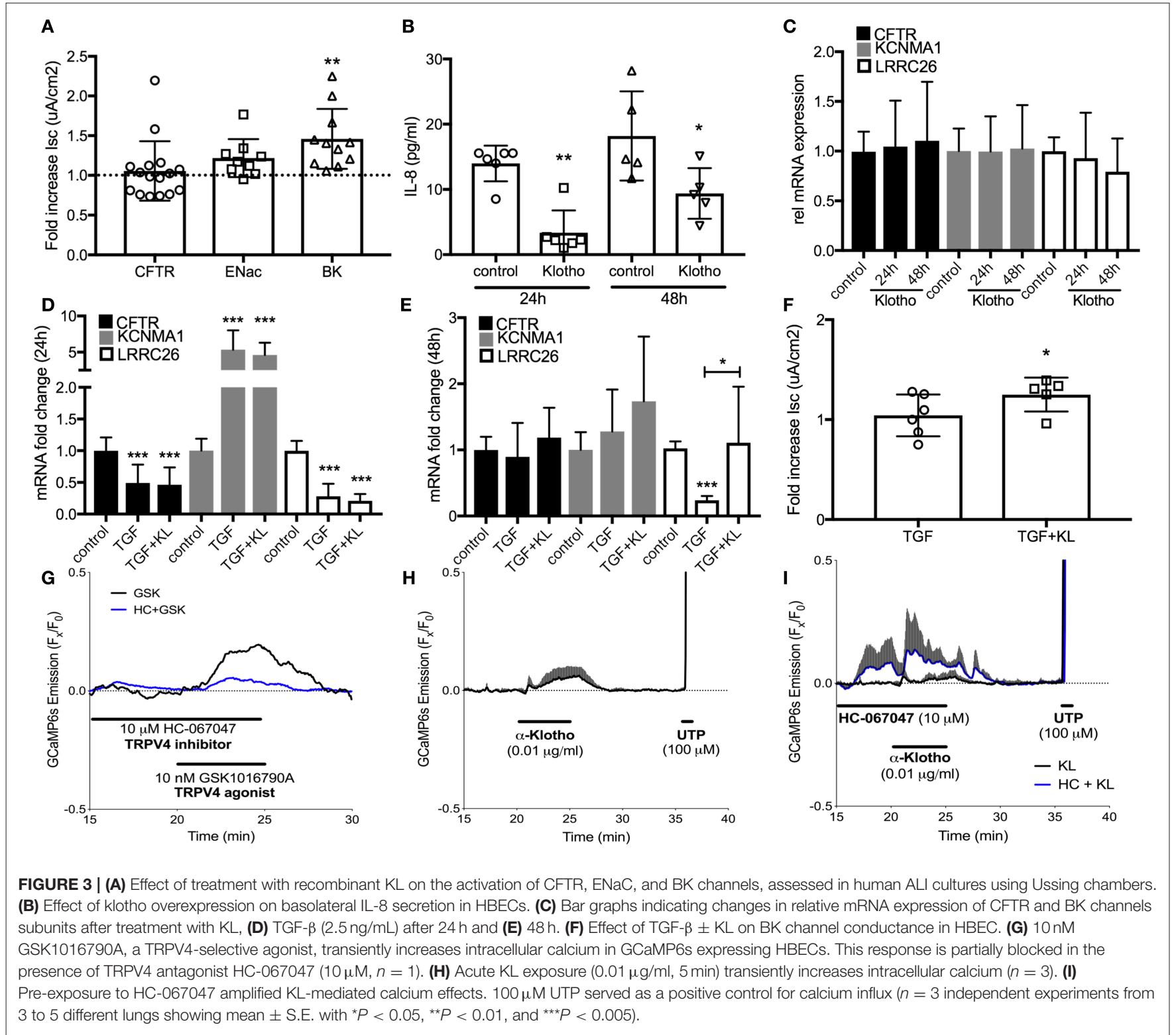




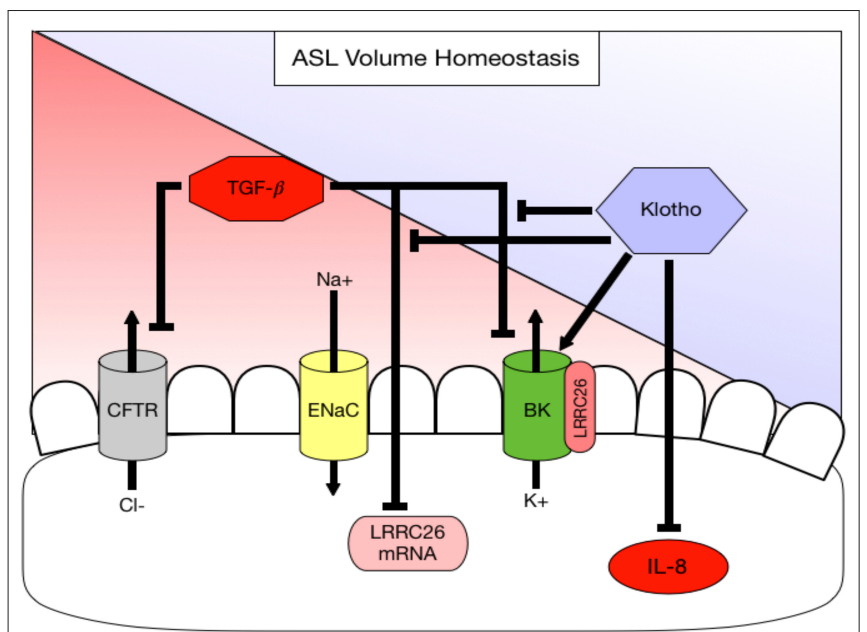

FIGURE 4 | Diagram summarizing working hypothesis. Klotho exerts an activating effect on the apical BK channel through a direct action but also indirectly by attenuating (1) a TGF- $\beta$-mediated decrease in LRRC26, the regulatory subunit of the BK channel and (2) a TGF- $\beta$-mediated inhibition of BK. In addition, klotho decreases basolateral IL- 8 secretion, which is pro-inflammatory thereby contributing to ASL volume dysregulation.

exerts an anti-inflammatory action in cystic fibrosis airway disease by counteracting TGF- $\beta$ signaling (26), but it is not clear how klotho affects the mucociliary transport apparatus. This study examines for the first time the role of klotho on mucociliary clearance ex vivo and in vitro and attempts to identify potential underlying mechanisms. Our results show that CBF was not affected in the klotho deficient mouse model, but that ASL volume, $\mathrm{CBF}$ and MCT are significantly reduced ex vivo and in vitro, which is paralleled by neutrophilic airway inflammation. In addition, we show that overexpression of klotho increased ASL volume. In order to identify a potential underlying mechanism, we showed that IL-8 levels were attenuated in klotho-overexpressing ALI-cultures. This is important, since IL8 has been shown to negatively regulate ASL volume $(10,17,45)$. Furthermore, klotho itself can increase intracellular calcium and affects BK channel activity, an apical potassium channel that has been shown to be involved in ASL homeostasis together with CFTR $(16,19)$. One potential mechanism could be through restoration of its regulatory subunit LRRC26 (Figure 4).

Klotho is expressed in the lung, but it is downregulated in airway diseases such as $\operatorname{COPD}(27,43,46)$. Interestingly, other reports have described an absence of klotho expression in the lung and suggested that it is synthesized in the kidney, cleaved at the transmembrane domain, released into the circulation and taken up by the lung $(47,48)$. Thus, more studies are needed to determine the exact organ genesis of klotho. However, the susceptibility to degradation and lack of sufficient tools to detect klotho make it difficult to study presently. Therefore, it was challenging for our studies to demonstrate overexpressed murine klotho, which made us therefore use both overexpression and exogenous stimulation for our studies. Using these approaches, there is sufficient evidence to prove that klotho clearly exerts effects on the lung and airways. Currently, klotho signaling is mainly linked to FGF23 signaling, where klotho functions as a co-receptor mediating phosphorylation of ERK (49). Recent studies suggest that there is not only klotho independent FGF23 signaling $(43,50)$ but also FGF23 independent klotho signaling $(51,52)$. We are aware that klotho deficient mice have elevated FGF23 levels, which could be responsible for mucociliary dysfunction, but we conducted all our in vitro assays in ALI cultures that do not express FGF23. Therefore, the klothomediated effects on mucociliary clearance should be independent of FGF23. We propose that the effect of klotho is two-fold: (1) klotho can directly activate the BK channel (Figure 3A) by an unknown mechanism, possibly through an increase of intracellular calcium (40); and (2) klotho can rescue the TGF$\beta$-mediated downregulation of LRRC26 and restore BK function (Figures 2, 3E). More mechanistic studies are needed to identify the exact signaling pathway. Importantly, these discoveries open new avenues of research to find anti-inflammatory and antiaging therapies for restoring klotho levels or increasing klotho signaling in the airway through the improvement of ASL volume and mucociliary clearance. These therapies would potentially benefit a variety of diseases that feature acute or chronic airway inflammation.

\section{DATA AVAILABILITY STATEMENT}

The datasets generated for this study are available on request to the corresponding author.

\section{ETHICS STATEMENT}

All experiments were approved by the University of Miami and University of Alabama at Birmingham (UAB) Institutional Animal Care and Use Committee (IACUC), and mice were housed in a UM or UAB facility approved by the Association for Assessment and Accreditation of Laboratory Animal Care (AAALAC). Written informed consent was obtained from the participants of this study. Standard biosecurity and institutional safety procedures have been adhered to.

\section{AUTHOR CONTRIBUTIONS}

SK and MS contributed to the concept and/or design of the study. SK, JG, ME, ES, JS, LK, GK, SC, JD, NB, and AA contributed to the acquisition of the data. SK, JG, CF, SR, JB, and MS contributed to the analysis and interpretation. JG and SK drafted the manuscript. All authors critically revised it for intellectual content and approved the final version prior to submission.

\section{FUNDING}

This work was supported by the Flight Attendant Medical Research Institute (YFAC152003; to SK and CIA160011 to MS) and the Cystic Fibrosis Foundation (CFF P30 DK072482 and CFF Rowe19RO; to SK; SALATH16G0 to MS), the NIA (R03AG059994 to SK), and the NIH (R01HL128714 to CF and R01HL133240, R01HL139365 to MS), and the James and Esther King Florida Biomedical Research Program (5JK02 to MS). 


\section{REFERENCES}

1. Salathe M, O'Riordan TG, Wanner A. Treatment of mucociliary dysfunction. Chest. (1996) 110:1048-57. doi: 10.1378/chest.110.4.1048

2. Wanner A, Salathe M, O'Riordan TG. Mucociliary clearance in the airways. Am J Respir Crit Care Med. (1996) 154:1868-902. doi: 10.1164/ajrccm.154.6.8970383

3. Tipirneni KE, Grayson JW, Zhang S, Cho DY, Skinner DF, Lim DJ, et al. Assessment of acquired mucociliary clearance defects using microoptical coherence tomography. Int Forum Allergy Rhinol. (2017) 7:920-5. doi: 10.1002/alr.21975

4. Hill DB, Long RF, Kissner WJ, Atieh E, Garbarine IC, Markovetz MR, et al. Pathological mucus and impaired mucus clearance in cystic fibrosis patients result from increased concentration, not altered pH. Eur Respir J. (2018) 52:1801297. doi: 10.1183/13993003.01297-2018

5. Stoltz DA, Meyerholz DK, Welsh MJ. Origins of cystic fibrosis lung disease. $N$ Engl J Med. (2015) 372:1574-5. doi: 10.1056/NEJMc1502191

6. Tang XX, Ostedgaard LS, Hoegger MJ, Moninger TO, Karp PH, McMenimen JD, et al. Acidic $\mathrm{pH}$ increases airway surface liquid viscosity in cystic fibrosis. J Clin Invest. (2016) 126:879-91. doi: 10.1172/JCI83922

7. Duncan GA, Jung J, Joseph A, Thaxton AL, West NE, Boyle MP, et al. Microstructural alterations of sputum in cystic fibrosis lung disease. JCI Insight. (2016) 1:e88198. doi: 10.1172/jci.insight.88198

8. Ramos FL, Krahnke JS, Kim V. Clinical issues of mucus accumulation in COPD. Int J Chron Obstruct Pulmon Dis. (2014) 9:139-50. doi: $10.2147 /$ COPD.S38938

9. Donaldson SH, Laube BL, Corcoran TE, Bhambhvani P, Zeman K, Ceppe A, et al. Effect of ivacaftor on mucociliary clearance and clinical outcomes in cystic fibrosis patients with G551D-CFTR. JCI Insight. (2018) 3:e122695. doi: $10.1172 /$ jci.insight. 122695

10. Boucher RC. Regulation of airway surface liquid volume by human airway epithelia. Pflugers Arch. (2003) 445:495-8. doi: 10.1007/s00424-002-0955-1

11. Song Y, Namkung W, Nielson DW, Lee JW, Finkbeiner WE, Verkman AS. Airway surface liquid depth measured in ex vivo fragments of pig and human trachea: dependence on $\mathrm{Na}+$ and Cl- channel function. Am J Physiol Lung Cell Mol Physiol. (2009) 297: L1131-40. doi: 10.1152/ajplung.00085.2009

12. Tarran R. Regulation of airway surface liquid volume and mucus transport by active ion transport. Proc Am Thorac Soc. (2004) 1:42-6. doi: $10.1513 /$ pats. 2306014

13. Boucher RC. Evidence for airway surface dehydration as the initiating event in CF airway disease. J Intern Med. (2007) 261:5-16. doi: 10.1111/j.1365-2796.2006.01744.x

14. Schmid A, Baumlin N, Ivonnet P, Dennis JS, Campos M, Krick S, et al. Roflumilast partially reverses smoke-induced mucociliary dysfunction. Respir Res. (2015) 16:135. doi: 10.1186/s12931-015-0294-3

15. Kis A, Krick S, Baumlin N, Salathe M. Airway hydration, apical $\mathrm{K}(+)$ secretion, and the large-conductance, $\mathrm{Ca}(2+)$-activated and Voltagedependent Potassium (BK) channel. Ann Am Thorac Soc. (2016) 13 (Suppl. 2):S163-8. doi: 10.1513/AnnalsATS.201507-405KV

16. Manzanares D, Gonzalez C, Ivonnet P, Chen RS, Valencia-Gattas M, Conner $\mathrm{GE}$, et al. Functional apical large conductance, $\mathrm{Ca} 2+$-activated, and voltagedependent $\mathrm{K}+$ channels are required for maintenance of airway surface liquid volume. J Biol Chem. (2011) 286:19830-9. doi: 10.1074/jbc.M110. 185074

17. Manzanares D, Srinivasan M, Salathe ST, Ivonnet P, Baumlin N, Dennis JS, et al. IFN-gamma-mediated reduction of large-conductance, $\mathrm{Ca} 2+$-activated, voltage-dependent $\mathrm{K}+(\mathrm{BK})$ channel activity in airway epithelial cells leads to mucociliary dysfunction. Am J Physiol Lung Cell Mol Physiol. (2014) 306:L453-62. doi: 10.1152/ajplung.00247.2013

18. Namkung W, Song Y, Mills AD, Padmawar P, Finkbeiner WE, Verkman AS. In situ measurement of airway surface liquid $\left[\mathrm{K}^{+}\right]$using a ratioable $\mathrm{K}^{+}$-sensitive fluorescent dye. J Biol Chem. (2009) 284:15916-26. doi: 10.1074/jbc.M808021200

19. Manzanares D, Krick S, Baumlin N, Dennis JS, Tyrrell J, Tarran R, et al. Airway surface dehydration by transforming growth factor beta (TGF-beta) in cystic fibrosis is due to decreased function of a voltage-dependent potassium channel and can be rescued by the drug pirfenidone. J Biol Chem. (2015) 290:25710-6. doi: $10.1074 /$ jbc.M115.670885
20. Raju SV, Solomon GM, Dransfield MT, Rowe SM. Acquired cystic fibrosis transmembrane conductance regulator dysfunction in chronic bronchitis and other diseases of mucus clearance. Clin Chest Med. (2016) 37:147-58. doi: $10.1016 /$ j.ccm.2015.11.003

21. Dransfield MT, Wilhelm AM, Flanagan B, Courville C, Tidwell SL, Raju $\mathrm{SV}$, et al. Acquired cystic fibrosis transmembrane conductance regulator dysfunction in the lower airways in COPD. Chest. (2013) 144:498-506. doi: $10.1378 /$ chest.13-0274

22. Wang Y, Sun Z. Current understanding of klotho. Ageing Res Rev. (2009) 8:43-51. doi: 10.1016/j.arr.2008.10.002

23. Mencke R, Harms G, Moser J, van Meurs M, Diepstra A, Leuvenink HG, et al. Human alternative Klotho mRNA is a nonsense-mediated mRNA decay target inefficiently spliced in renal disease. JCI Insight. (2017) 2:e94375. doi: 10.1172/jci.insight. 94375

24. Quarles LD. Endocrine functions of bone in mineral metabolism regulation. J Clin Invest. (2008) 118:3820-8. doi: 10.1172/JCI36479

25. Doi S, Zou Y, Togao O, Pastor JV, John GB, Wang L, et al. Klotho inhibits transforming growth factor-beta1. (TGF-beta1) signaling and suppresses renal fibrosis and cancer metastasis in mice. J Biol Chem. (2011) 286:8655-65. doi: 10.1074/jbc.M110.174037

26. Krick S, Baumlin N, Aller SP, Aguiar C, Grabner A, Sailland J, et al. Klotho inhibits interleukin-8 secretion from cystic fibrosis airway epithelia. Sci Rep. (2017) 7:14388. doi: 10.1038/s41598-017-14811-0

27. Gao W, Yuan C, Zhang J, Li L, Yu L, Wiegman CH, et al. Klotho expression is reduced in COPD airway epithelial cells: effects on inflammation and oxidant injury. Clin Sci. (2015) 129:1011-23. doi: 10.1042/CS20150273

28. Hu MC, Shi M, Cho HJ, Adams-Huet B, Paek J, Hill K, et al. Klotho and phosphate are modulators of pathologic uremic cardiac remodeling. J Am Soc Nephrol. (2015) 26:1290-302. doi: 10.1681/ASN.2014050465

29. Krick S, Wang J, St-Pierre M, Gonzalez C, Dahl G, Salathe M. Dual oxidase 2 (Duox2) regulates pannexin 1-mediated ATP release in primary human airway epithelial cells via changes in intracellular $\mathrm{pH}$ and not $\mathrm{H} 2 \mathrm{O} 2$ production. J Biol Chem. (2016) 291:6423-32. doi: 10.1074/jbc.M115.664854

30. Kuro-o M, Matsumura Y, Aizawa H, Kawaguchi H, Suga T, Utsugi T, et al. Mutation of the mouse klotho gene leads to a syndrome resembling ageing. Nature. (1997) 390:45-51. doi: 10.1038/36285

31. You Y, Brody SL. Culture and differentiation of mouse tracheal epithelial cells. Methods Mol Biol. (2013) 945:123-43. doi: 10.1007/978-1-62703-125-7_9

32. Chen X, Baumlin N, Buck J, Levin LR, Fregien N, Salathe M. A soluble adenylyl cyclase form targets to axonemes and rescues beat regulation in soluble adenylyl cyclase knockout mice. Am J Respir Cell Mol Biol. (2014) 51:750-60. doi: 10.1165/rcmb.2013-0542OC

33. Birket SE, Davis JM, Fernandez CM, Tuggle KL, Oden AM, Chu KK, et al. Development of an airway mucus defect in the cystic fibrosis rat. JCI Insight. (2018) 3:e97199. doi: 10.1172/jci.insight.97199

34. Liu L, Chu KK, Houser GH, Diephuis BJ, Li Y, Wilsterman EJ, et al. Method for quantitative study of airway functional microanatomy using micro-optical coherence tomography. PLoS ONE. (2013) 8:e54473. doi: 10.1371/journal.pone.0054473

35. Liu L, Shastry S, Byan-Parker S, Houser G, K Chu K, Birket SE, et al. An autoregulatory mechanism governing mucociliary transport is sensitive to mucus load. Am J Respir Cell Mol Biol. (2014) 51:485-93. doi: 10.1165/rcmb.2013-0499MA

36. Schneider CA, Rasband WS, Eliceiri KW. NIH image to imageJ: 25 years of image analysis. Nat Methods. (2012) 9:671-5. doi: 10.1038/nmeth.2089

37. Sailland J, Grosche A, Baumlin N, Dennis JS, Schmid A, Krick S, et al. Role of Smad3 and p38 signalling in cigarette smoke-induced CFTR and BK dysfunction in primary human bronchial airway epithelial cells. Sci Rep. (2017) 7:10506. doi: 10.1038/s41598-017-11038-x

38. Shiraki-Iida T, Aizawa H, Matsumura Y, Sekine S, Iida A, Anazawa $\mathrm{H}$, et al. Structure of the mouse klotho gene and its two transcripts encoding membrane and secreted protein. FEBS Lett. (1998) 424:6-10. doi: 10.1016/S0014-5793(98)00127-6

39. Baumlin-Schmid N, Salathe M, Fregien NL. Optimal lentivirus production and cell culture conditions necessary to successfully transduce primary human bronchial epithelial cells. J Vis Exp. (2016) 113:e54176. doi: 10.3791/54176

40. Chung S, Baumlin N, Dennis JS, Moore R, Salathe SF, Whitney PL, et al. Electronic cigarette vapor with nicotine causes airway mucociliary 
dysfunction preferentially via TRPA1 receptors. Am J Respir Crit Care Med. (2019) 200:1134-45. doi: 10.1164/rccm.201811-2087OC

41. Chen TW, Wardill TJ, Sun Y, Pulver SR, Renninger SL, Baohan A, et al. Ultrasensitive fluorescent proteins for imaging neuronal activity. Nature. (2013) 499:295-300. doi: 10.1038/nature12354

42. Salathe M, Bookman RJ. Coupling of [Ca2+]i and ciliary beating in cultured tracheal epithelial cells. J Cell Sci. (1995) 108:431-40.

43. Krick S, Grabner A, Baumlin N, Yanucil C, Helton S, Grosche A, et al. Fibroblast growth factor 23 and klotho contribute to airway inflammation. Eur Respir J. (2018) 52:1800236. doi: 10.1183/13993003.00236-2018

44. Unwalla HJ, Ivonnet P, Dennis JS, Conner GE, Salathe M. Transforming growth factor-betal and cigarette smoke inhibit the ability of beta2-agonists to enhance epithelial permeability. Am J Respir Cell Mol Biol. (2015) 52:65-74. doi: $10.1165 / \mathrm{rcmb} .2013-0538 \mathrm{OC}$

45. Galietta LJ, Folli C, Caci E, Pedemonte N, Taddei A, Ravazzolo R, et al. Effect of inflammatory stimuli on airway ion transport. Proc Am Thorac Soc. (2004) 1:62-5. doi: 10.1513/pats.2306017

46. Li L, Wang Y, Gao W, Yuan C, Zhang S, Zhou H, et al. Klotho reduction in alveolar macrophages contributes to cigarette smoke extract-induced inflammation in chronic obstructive pulmonary disease. J Biol Chem. (2015) 290:27890-900. doi: 10.1074/jbc.M115.655431

47. Gazdhar A, Ravikumar P, Pastor J, Heller M, Ye J, Zhang J, et al. Alphaklotho enrichment in induced pluripotent stem cell secretome contributes to antioxidative protection in acute lung injury. Stem Cells. (2018) 36:616-25. doi: 10.1002/stem.2752

48. Ravikumar P, Ye J, Zhang J, Pinch SN, Hu MC, Kuro-o M, et al. alpha-Klotho protects against oxidative damage in pulmonary epithelia. Am J Physiol Lung Cell Mol Physiol. (2014) 307:L566-75. doi: 10.1152/ajplung.00306.2013
49. Grabner A, Mazzaferro S, Cianciolo G, Krick S, Capelli I, Rotondi S, et al. Fibroblast growth factor 23: mineral metabolism and beyond. Contrib Nephrol. (2017) 190:83-95. doi: 10.1159/000468952

50. Grabner A, Amaral AP, Schramm K, Singh S, Sloan A, Yanucil C, et al. Activation of cardiac fibroblast growth factor receptor 4 causes left ventricular hypertrophy. Cell Metab. (2015) 22:1020-32. doi: 10.1016/j.cmet.2015. 09.002

51. Dalton G, An SW, Al-Juboori SI, Nischan N, Yoon J, Dobrinskikh E, et al. Soluble klotho binds monosialoganglioside to regulate membrane microdomains and growth factor signaling. Proc Natl Acad Sci USA. (2017) 114:752-7. doi: 10.1073/pnas.162 0301114

52. Wright JD, An SW, Xie J, Lim C, Huang CL. Soluble klotho regulates TRPC6 calcium signaling via lipid rafts, independent of the FGFR-FGF23 pathway. FASEB J. (2019) 33:9182-93. doi: 10.1096/fj.201900321R

Conflict of Interest: The authors declare that the research was conducted in the absence of any commercial or financial relationships that could be construed as a potential conflict of interest.

Copyright $\odot 2020$ Garth, Easter, Skylar Harris, Sailland, Kuenzi, Chung, Dennis, Baumlin, Adewale, Rowe, King, Faul, Barnes, Salathe and Krick. This is an openaccess article distributed under the terms of the Creative Commons Attribution License (CC BY). The use, distribution or reproduction in other forums is permitted, provided the original author $(s)$ and the copyright owner(s) are credited and that the original publication in this journal is cited, in accordance with accepted academic practice. No use, distribution or reproduction is permitted which does not comply with these terms. 